\title{
El ecosistema virtual de los niños
}

\author{
Amaia Arribas Urrutia* \\ Instituto Tecnológico y de Estudios Superiores de Monterrey, \\ Campus Estado de MÉXico
}

La revolución que ha supuesto la aparición de las diferentes pantallas ha convertido tanto a niños como jóvenes en protagonistas del cambio que estamos viviendo. Ambos públicos son capaces de comunicarse, estudiar y entretenerse a través de una pantalla, bien sea la televisión, la computadora, el celular, los videojuegos o Internet. Sus formas de comunicación y entretenimiento han cambiado al igual que su concepto de aprendizaje. Ante ello, hay que reconocer la importante oportunidad que representa para los niños, desde la enseñanza, pasando por las relaciones sociales y el entretenimiento. Los mundos virtuales y las redes sociales para nińos se han convertido en el modus operandi de sus comunicaciones: los niños no sólo conocen a nuevos niños y profundizan en sus relaciones con estos nińos que acaban de conocer en Internet, sino que también prolongan sus relaciones con niños que ya conocen en la vida "normal".

El objetivo de este trabajo es aportar una visión panorámica sobre el uso que están haciendo los niños de Internet para su entretenimiento y relación social (no se tratará en este artículo las webs de juegos ni de educación por Internet), desde una perspectiva positivista que trata de ver en Internet una fuente de desarrollo de habilidades sociales y de conocimiento, frente a los apocalípticos que ven en Internet una amenaza para

* Doctora en Comunicación por la upv (España), Maestra en Dirección de Comunicación Institucional y Empresarial por la UAB (Espańa)), y Licenciada en Periodismo por la upv (España). Desarrolla su actividad investigadora en comunicación organizacional en publicaciones nacionales e internacionales, y participa con ponencias en diversos foros de comunicación social. Profesora-Investigadora en la Cátedra de Comunicación Estratégica y Cibercultura del Tecnológico de Monterrey, Campus Estado de México. Correo electrónico: amaya.arribas@itesm.mx 
los niños. Este texto refleja una descripción de webs para niños y una reflexión sobre estos nuevos medios de comunicación entre los niños.

Palabras clave: Mundos virtuales, redes sociales, niños, Internet

The revolution that has supposed the appearance of the different screens has turned children as well as young people into protagonists of the change we are living. Both audiences are able to communicate, to study and to entertain themselves through a screen; either it is a television, a computer, a mobile phone, videogames, or the Internet. Their ways of communication and entertainment have change as well as their learning concept. Before this, we must acknowledge the big opportunity that this represents for children, beginning from the learning, passing through the social relationships and the entertainment. The virtual worlds and the social networks for kids have become the modus operandi in their communications: not only they know new kids and deep relations with this kids that have just known in the Internet, but also they extend their relationships with kids they know in the "normal" life.

The objective of this article is to contribute a panoramic vision on the use that Kids are doing of Internet for their entertainment and social relations (I will not cover the webs for playing, neither for education), and all since a perspective positivist that tries to see on Internet a social abilities development source and a knowledge one, against the apocalyptic point of views that see on Internet a threat for the Kids. This article shows a description of websites for kids and a reflection about these new mass media among the kids.

Keywords: Virtual worlds, social networks, kids, Internet

\section{INTRODUCCIÓN}

Actualmente, puede hablarse de una Generación Net o de Nativos digitales ${ }^{l}$ para referirnos a niños de más de 6 años que no experimentan con la Red, como nosotros, sino que la usan de manera natural y espontánea. Para estos niños, el uso de los dispositivos digitales o gadgets es habitual puesto que han nacido rodeados de computadoras.

La relación de los niños con Internet es diferentes considerando las diferentes edades: de 2 a 4 años es el comienzo, su uso es muy limitado, y la computadora

${ }^{1}$ Como señala Sandra Dávila, "Esta Generación-Net está conformada por las personas que para el año 1999 tenían de 0 a 20 años. Esta Generación tiene características de actuación, mente, pensamiento y procesamiento muy distintas a las de las anteriores generaciones (sus padres y demás ascendentes), en consecuencia demanda formas distintas de vida, consistentes en quehaceres -desde los más cotidianos hasta los más complejos - con características igualmente distintas a las de esa anterior generación". 
no juega un papel significativo, aunque, ofrece, a través de CD's o programas de actividades (como sugerencia a los papás está el enseñar el uso de teclado, ratón, $\mathrm{CD}$, disquetera y disponer de tiempo para compartir actividades en la computadora); a partir de los 5 años es cuando empiezan a navegar ellos solos; de 7 a 8 ańos crece su interés por Internet, y de 9 a 12 ańos ya son verdaderos expertos en línea. En esta edad, la preadolescencia, todo lo quieren saber, y han oído que todo está en la Red.

Entre los 4 y 6 años el uso de la computadora no es una prioridad, pero se adquieren habilidades motoras que permiten hacer un mayor uso de los juegos, productos educativos y otros programas. Se puede empezar a explorar secciones para nińos dentro de Internet, acompañados de sus padres, ya que aunque los niños aprenden de manera intuitiva y rápidamente, a esta edad dependen de sus papás para leer e interpretar. A esta edad puede iniciarse el uso compartido del correo electrónico con el nińo, de manera que pueda conocer sus contenidos. A partir de los 6 años, el niño comienza a experimentar y apreciar mucho más sus actividades en Internet (uso de enciclopedias en línea, tareas escolares, tener amigos en línea).

Para estos niños, considerando en este texto la niñez desde los 6 hasta los 12 años, las palabras descarga, navegar, webcam, correo electrónico y chatear ya forman parte de su vocabulario habitual: en el salón de clase a través de webcam han podido conversar con niños de otros países y compartir ideas sobre un tema. Incluso alguno ha subido su video a Youtube (http://www.youtube. com) para que los otros nińos lo puedan ver. Al llegar a casa, hacen sus tareas en modo multitarea ya que las realizan escuchando música en su iPod, y entre una cosa y otra envían algún que otro mensaje de texto a sus amigos.

\section{HÁBITOS Y CONSUMO}

En la actualidad, diferentes estudios sobre los hábitos infantiles revelan que los nińos dedican tanto tiempo a navegar por Internet que muchas empresas les están dedicando gran parte de su presupuesto publicitario. Mientras los medios tradicionales se preguntan dónde están los niños y adolescentes que antes formaban parte de su audiencia, varias compañías están dedicadas a la creación de series para Internet, donde los usuarios pueden interactuar con los protagonistas e influir en la historia o crear una nueva.

Un estudio interesante sobre el uso que hacen los niños y adolescentes de la tecnología es el elaborado por la Fundación Telefónica y la Universidad de 
Navarra, titulado Generaciones Interactivas en Iberoamérica. Nińos y adolescentes frente a las pantallas. Retos educativos y sociales (véase, Figura 1). Este estudio, que tiene el objetivo de conocer el comportamiento de los nińos en el mercado de la comunicación iberoamericana para ofrecer soluciones a padres y educadores, fue realizado entre julio y octubre de 2007 a veintidos mil niños y adolescentes de 7 países latinoamericanos, entre los que se encuentran México, Argentina, Brasil, Chile, Colombia, Perú y Venezuela, y revela que el $42 \%$ de los nińos encuestados de 11 años prefieren Internet a la televisión y el porcentaje sube hasta el $60 \%$ en el rango de adolescentes entre 14 y 15 años, incluso aunque no dispongan de acceso Internet, navegan de forma autónoma y utilizan los celulares para su ocio y entretenimiento, más allá que como pura herramienta de comunicación.

Para los niños y adolescentes estar "desconectado" o no tener acceso a Internet significa estar prácticamente "muertos", socialmente hablando. Según una encuesta realizada por la Asociación Mexicana de Internet (AMIPCI), publicada el pasado mes de mayo, el $92 \%$ de los niños y adolescentes mexicanos consideraron que Internet es el medio de comunicación indispensable para ellos. Por ello, según este estudio, en promedio al día pasan tres horas frente a alguna computadora o cualquier otro dispositivo electrónico que les permite conectarse a Internet. En definitiva, todo aquello que implique interactividad y diálogo es oportunidad clara de conexión con esta generación net.

Otros datos destacables sobre el estudio sobre las generaciones interactivas en Iberoamérica es que navegar solo por Internet es la opción mayoritaria entre los niños de 10 a 14 años. De éstos, el 20\% reconoce fingir ser otra persona en los chats; el $30 \%$ ha quedado en la vida real con alguien que ha conocido en Internet. Además, de este grupo sólo el $8 \%$ considera la red un capricho; y la navegación solitaria se hace también sin filtro (sólo un 10\%). Esta información nos advierte el peligro que hay para muchos niños que acceden a información no apta para su edad, o en el peor de los casos, son contactados por personas adultas para fines peligrosos.

El estudio advierte que aquellos niños que no poseen acceso a la Red, ésta se configura como una aspiración, y acceden a Internet de forma autónoma sin contar con supervisión. Respecto a la telefonía celular, la encuesta indica que aunque la utilizan para llamar y recibir llamadas $(81 \%)$ y para enviar y recibir mensajes de texto (74\%), la investigación señala que más de la mitad utiliza los dispositivos móviles para jugar, el 45\% también escucha música y el 48\% ve fotos o videos con ellos.

304 Amaia Arribas Urrutia 
La encuesta señala que los niños que cuentan con apoyo en la navegación por Internet desde sus escuelas encuentran Internet más útil para su vida, más conscientes de los beneficios de una conexión segura a la Red, son más críticos con el medio, e incluso son más activos como para crear una página web propia.

La Generación Net es autodidacta. No obstante, los datos recogidos hasta el momento ponen de manifiesto que existen diferencias en el uso y percepción de la Red entre aquellos que navegan y aprenden a navegar desde la escuela y los que no lo hacen.

Figura I

Uso de Internet según se navegue desde la escuela o no (\%)

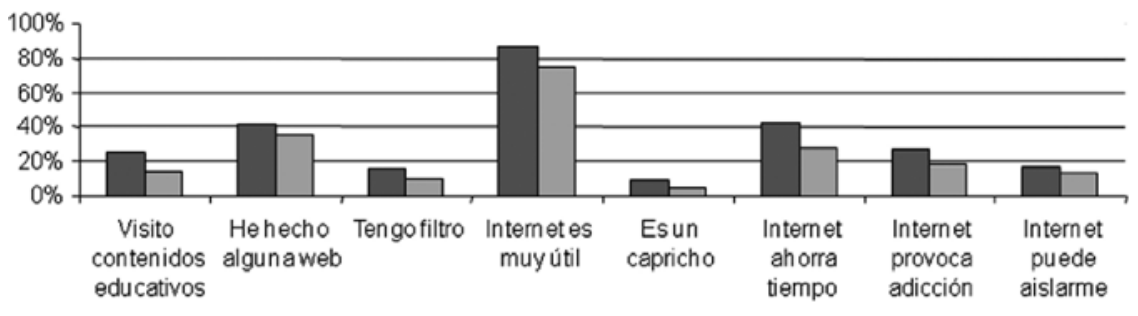

- Navego en la escuela $\square$ Noutilizo Internet en la escuela

Fuente: Fundación Telefónica y Universidad de Navarra (2007). Generaciones Interactivas en Iberoamérica. Niños y adolescentes frente a las pantallas. Retos educativos y sociales

La fractura digital sigue siendo real en Iberoamérica lo que supone un verdadero problema educativo. Un ejemplo: diferencias entre escolares de 10 a 12 años que navegan con su mamá frente a aquellos que lo hacen de forma habitual solos. Si bien los datos parecen sugerir una idea: la ventaja tecnológica de la Generación Interactiva, por grande que sea, no supera el potencial de padres y madres volcados en la educación de sus hijos.

Los niños que navegan con su mamá navegan en Internet con filtro, visitan páginas con contenidos educativos, y piensan que Internet puede aislarles y generar adicción. En cambio, los nińos que navegan solos consideran que Internet les quita tiempo de estar con su familia. Es de resaltar que el porcentaje más alto es el que considera que Internet le quita tiempo de estudio (35\%). Ello nos hace pensar que todavía los niños y jóvenes no están aprovechando Internet para el aprendizaje y sólo lo utilizan para el entretenimiento.

A pesar de que la Generación Net prefiere las nuevas tecnologías a los medios tradicionales para entretenerse, la vinculación con sus papás en la educación sigue 
siendo predominante. Aún más. Se puede hablar de familias digitales. Según un estudio integrado en el informe global de Mediascope Europe de la Asociación Europea de Publicidad Interactiva publicado recientemente, las personas que viven con niños se conectan más que las que no conviven con niños, y en consecuencia, realizan muchas más actividades en Internet que las que no viven con niños.

Si bien los datos reflejan los hábitos de las familias digitales europeas, son un reflejo también de lo que sucede en muchas familias latinoamericanas: los papás digitales ven películas en Internet (aquellos cuyo ancho de banda se lo permite), escuchan radio online, consultas comparativas de productos, y crean contenidos. El tiempo que pasan en Internet es cada vez mayor, incluso podríamos decir que es directamente proporcional al tiempo que dedican sus hijos, siendo las familias con hijos las que suelen estar más tiempo conectadas los fines de semana que las que no tienen hijos.

Otra situación que debemos considerar es que el consumo de Internet está disminuyendo el consumo de otros medios tradicionales: se ve menos televisión, se leen menos periódicos y menos revistas, se escucha menos la radio. Eso sí, hay que considerar que estos medios los leen en Internet por lo que no significa que se esté menos informado. La razón de hacerlo por Internet es porque les provee de lo que quieren más rápidamente.

Las páginas más visitadas por los papás digitales, así como las actividades que realizan, varían mucho en relación con la edad de sus hijos. Por ejemplo, los papás que tienen hijos de 0 a 4 años, visitan webs sobre salud y cine. En cambio, aquellos cuyos hijos tienen entre 5 y 9 años visitan páginas sobre juegos. Los papás que tienen hijos de entre 10 y 15 visitan webs sobre comparativas de productos, mientras que los papás con jóvenes entre 16 y 18 años navegan más las webs de contenidos audiovisuales.

Esta investigación también señala que las personas que viven con niños están más preparadas en cuanto a los gadgets tecnológicos gracias a que conviven con niños y adolescentes que las manejan con gran destreza, ya que disponen de una amplia experiencia con artilugios y dispositivos (teléfono celular, la PDA o la blackberry).

En México, según el último "Estudio de consumo e Internet del IAB" (Interactive Advertising Bureau -http://www.iabmexico.com-), llevado a cabo por Millward Brown y TG $^{\mathrm{TM}}$, publicado en julio de 2008 en México, revela que Internet es actualmente el tercer medio más utilizado en México, después de la televisión y la radio, donde el usuario pasa alrededor de de 4.49 horas cada vez que se "conecta a Internet", de los cuales lo hace de manera activa durante 3.56 horas por 
ocasión. De acuerdo a los datos de penetración de Internet proporcionados por TGI, 3 de cada 10 mexicanos acceden a este medio. Otro dato relevante según esta fuente es que cada vez más mexicanos tienen acceso a Internet, siendo utilizado ya por más del $20 \%$ de la población y más del $26 \%$ en zonas urbanas.

Para entender las características demográficas de Internet, a través de TGI se hizo un análisis que señaló que Internet tiene una penetración del 32\% de la población nacional. Estos internautas se conectan un promedio de 17 veces al mes y hacen de sus dispositivos digitales (computadoras, cámaras, reproductores de $M P 3$ y teléfonos celulares) parte de su vida cotidiana. La segunda parte del estudio, mediante una encuesta en línea), permitió captar una muestra de 2,027 personas mayores de 14 años de todos los niveles socioeconómicos, de todo México.

El estudio señaló que el hogar y el lugar de trabajo son los sitios donde se conecta la gente generalmente, pero no contar con conexión en Internet en casa no es obstáculo para ser un internauta sobre todo en los niveles socioeconómicos bajos. El papel de los cibercafés es fundamental para entender por tanto el acceso a Internet en México en estos sectores.

La multitarea está presente: los internautas realizan otras actividades simultáneamente al uso de Internet: teléfono, música y televisión son los medios que utilizan a la vez cuando están navegando. Actualmente, la penetración de equipos electrónicos digitales es considerablemente alta entre los internautas. En la figura siguiente se aprecia los artículos que poseen los internautas mexicanos.

Figura 2

Articulos que poseen los internautas mexicanos

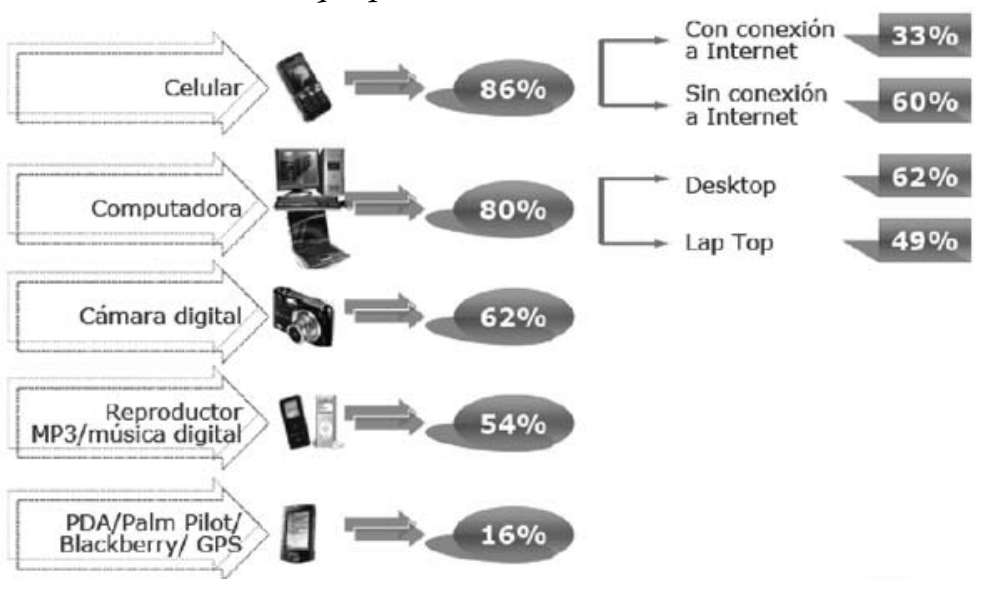

Fuente: IAB México, 2008 
Es importante considerar que existe una generación de jóvenes de 18 a 24 años, que vive en línea, bien en la Red, con su iPod o celular. Lo que les importa es estar conectados. Por eso, Internet un estilo de vida para muchos, no sólo para los jóvenes sino para otros segmentos de edades también. En este estudio, para los internautas mexicanos, Internet se vuelve el medio con el mayor vínculo emocional. Frases como "disfruto utilizarlo", "forma parte de mi vida cotidiana", "es indispensable en mi vida" o "lo amo" son atributos asociados a Internet.

También Internet es considerado un medio funcional ya que los internautas señalan que Internet les mantiene actualizado, marca tendencias, lo usan más que cualquier otro medio de comunicación, y les permite decidir lo que ven, leen y escuchan (sienten que les otorga el poder de decisión, son más proactivos).

En definitiva, en el estudio de IAB sobre México se dibuja como un documento de alcance, ya que reúne a diversos grupos poblacionales, incluso aquellos que tradicionalmente estaban alejados del mundo interactivo. Internet no sólo forma parte de la vida cotidiana de los usuarios, sino que ha conseguido generar un vínculo afectivo que aporta un sentido de pertenencia y de comunidad (véase las redes sociales) y a la vez, de independencia.

Por último, otra investigación realizada por Yahoo México, formando parte de un estudio ambicioso que se ha realizado a nivel mundial en el que han participado 16 países de Asia, Europa, Australia y América, con un total de 4,783 encuestados mayores de 18 años, revela datos muy interesantes en relación a medios de comunicación y propiedad de la tecnología, uso y actitudes y valores.

El hogar promedio con Internet tiene 2.4 televisores, dos computadoras y 6.3 dispositivos tecnológicos de otro tipo. Ya en México podemos ver que otros dispositivos como cámara digital, HDTV, seguido de la televisión, supera a las computadoras.

Figura 3

Número promedio de dispositivos tecnológicos que tiene cada familia

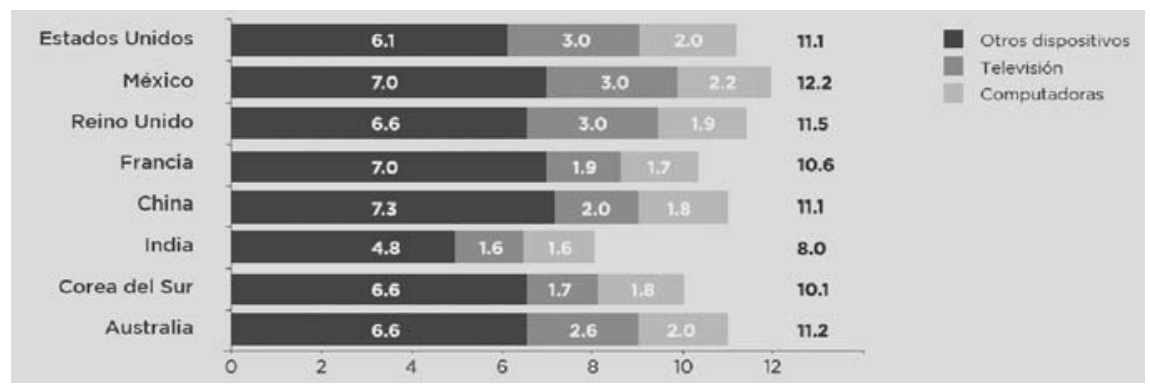

Fuente: IAB México 
El teléfono celular está omnipresente, mientras que otros tipos de tecnología varían por país. México y Reino Unido tienen la adopción más alta de celular, y Asia encabeza la lista en la adopción de reproductores MP3.

Normalmente, las personas pasan un cuarto del total de horas del día utilizando medios de comunicación. México está en el promedio con casi el 20\% del tiempo útil del día en medios de comunicación (los encuestados que más tiempo consumen en medios es la India). De ese tiempo, los mexicanos pasan más horas con tecnologías que con otros medios convencionales.

Cada vez se utiliza más el término familia 2.0, primero porque las encuestas arrojan que la mayoría de los encuestados desea y disfruta pasar tiempo con su familia; y segundo, porque muchas de las actividades que realizan juntos tienen que ver con los dispositivos y pantallas digitales (las llamadas en celular, los mensajes cortos, el correo electrónico, twitter, Messenger, escuchar música en Internet, juegos en línea, compartir fotografías). Finalmente, Internet y la televisión educan, informan y entretienen a los miembros de la familia.

Si para los papás es todo un reto educar teniendo como instrumento Internet, para los maestros se ha vuelto toda una revolución educativa. Las tecnologías cambian muy rápido, y en la mayoría de las ocasiones, los niños tienen un mejor conocimiento de ellas que sus papás o maestros. Gigantes de la informática e Internet como Microsoft, Google y Yahoo, así como portales de redes sociales como FaceBook y Myspace han participado en la iniciativa (disponible en seis idiomas: inglés, español, francés, italiano, checo y alemán) con operadores como el francés Orange, el británico Vodafone y el alemán Deutsche Telekom, un portal de Internet para ayudar a los maestros a enfrentar mejor el uso de las nuevas tecnologías por parte de sus alumnos.

Además, Internet se convierte en un fenómeno social entre niños y adolescentes en el momento en que se crean comunidades virtuales. Internet supone un verdadero reto educativo al integrar la Red en la metodología docente, descubriéndose la escuela como un factor esencial para formar en el uso del medio, eso sí, conciliando sus posibles riesgos.

Tapscott (1998) señala que al explorar los medios digitales e Internet, tanto educadores como estudiantes pueden desarrollar un paradigma de aprendizaje nuevo y poderoso. Indica que la Generación Net necesita un aprendizaje interactivo y propone ocho cambios hacia la materialización del mismo:

1. De un aprendizaje lineal al aprendizaje con hipermedia.

2. De la instrucción al descubrimiento. 
3. De la educación centrada en el maestro, a la educación centrada en el estudiante.

4. De absorber material a aprender cómo navegar y cómo aprender.

5. Del aprendizaje en la escuela al aprendizaje durante la vida.

6. Del aprendizaje ajustado a todos, al aprendizaje personalizado.

7. Del aprendizaje como tortura al aprendizaje como diversión.

8. Del maestro como transmisor al maestro como facilitador.

Por otro lado, hay que tener en cuenta que el acceso a Internet tampoco garantiza el aprendizaje en automático. El capital cultural así como los procesos de socialización tecnológica de niños de diferentes niveles socio-culturales crean distintos contextos de apropiación de la cultura Internet. Algunos niños que ya tienen un recorrido previo por la tecnología se mueven con fluidez y llegan preparados para transitar en la Red. En cambio, otros están extraviados "navegando" e intentando lidiar con sus dificultades técnicas, y un bajo bagaje en su capital cultural por lo que "naufragan" con facilidad.

Con esto, queremos decir que las ventajas que tiene Internet para los niños no vienen dadas por sí solas, sino que tiene que haber un contexto propicio y una actitud proactiva de los padres para que realmente los nińos lleguen a sacar todas las posibilidades de Internet.

El uso intensivo que hacen de Internet plantea muchas incógnitas sobre cómo influirá en sus relaciones sociales, familiares, en su capacidad de percepción y de expresión, En definitiva, en qué medida las tecnologías están contribuyendo a la formación de su personalidad.

\section{Mundos VirTuales}

Los mundos virtuales representan otro escenario en Internet donde los niños se están adentrando. Las compañías mediáticas tradicionales están buscando insertar sus marcas a los mundos virtuales de tres dimensiones, buscando tres objetivos: construir comunidades en internet, incrementar el conocimiento de su marca y lograr así acceder a los consumidores.

La empresa de investigación Forrester Research dio a conocer en enero de este año un informe sobre mundos virtuales titulado Getting Real Work Done In Virtual Worlds, en el que llegó a la conclusión de que en cinco ańos, Internet 3D será tan importante para el mundo profesional como lo es hoy la Web. En el informe señalan algunas investigaciones realizadas por Iвм e Intel en las que 
afirman que se debe experimentar con los mundos virtuales. Por ejemplo, las posibilidades de comunicación no verbal y la mayor experiencia física de los mundos virtuales, ante las conferencias o reuniones a través de otras herramientas de Internet. Gracias a las plataformas 3D se conseguiría una experiencia de comunicación más real y completa.

En el caso de los niños, sus mundos virtuales son versiones en línea de juegos imaginarios. A diferencia de las redes sociales, los mundos virtuales permiten a los niños interactuar con avatares (representaciones gráficas en el mundo virtual de los propios nińos) en tres dimensiones, que son controlados por los niños cuando interaccionan y se relacionan con otros niños que han creado personajes parecidos.

Hay toda una nueva moda de páginas web que ofrecen mundos virtuales para niños donde pueden vestir muñecas, cuidar animales o disfrazar a personajes en juegos en línea. En estos mundos, las muñecas, los animales y los personajes son avatares.

También los medios de comunicación se suman a la creación de mundos virtuales. Así, la cadena $\mathrm{CBBC}$, filial de la $\mathrm{BBC}$ dispone de un nuevo mundo internauta poblado exclusivamente por niños, $C B B C$ World. Es una vida similar a Second Life ${ }^{2}$ para niños de entre 7 y 12 años, y cuya principal característica es la seguridad y el control de contenidos (sin chat). Los niños tienen múltiples opciones para crear un personaje a su gusto que después les permitirá interactuar. Además de acceder a contenidos audiovisuales, los niños también pueden crearlos y compartirlos, teniendo la oportunidad de construir un lugar de acuerdo con su propia imaginación.

El mundo virtual de Adventure Rock (http://www.bbc.co.uk/cbbc/adventurerock) es un juego interactivo de la BвC en Internet y destinado a niños de entre 6 y 12 años, donde fantasean en una isla, explorando el mundo, utilizando tableros de mensajes para compartir lo que han descubierto y lo que han hecho en cada uno de los espacios esparcidos en el escenario virtual. Se realizó una investigación en la Universidad de Westminster donde se analizó las formas

\footnotetext{
${ }^{2}$ La economía de Second Life sigue creciendo a pesar de que algunos dan por terminado Second Life. Las horas de conexión de los usuarios aumenta, así como el número de conectados simultáneos, eso sí, de forma lenta. Second Life se erige como el lugar donde socializar virtualmente, fantasear y desarrollar la propia creatividad. Además, se utiliza como plataforma de ocio y negocios para pequeños emprendedores. Fuente de consulta: http://blogs.periodistadigital. $\mathrm{com} /$ mundovirtual.php?blog=768\&page $=1 \&$ disp=posts \&paged $=2$. Fecha de consulta 25 de abril de 2008 .
} 
en que los niños utilizaban este mundo virtual y expresaron sus reacciones sobre los aspectos positivos y negativos. El estudio reveló que los nińos podían asumir uno de ocho roles cuando exploraban el mundo virtual. Los papeles incluían el de explorador, combatientes, consumidores, cultivadores o creadores de sistemas de vida. Se descubrió que los niños podían ser en algún momento exploradores y en otros consumidores deseosos de conectarse con otros jugadores o bien usuarios sofisticados del juego analizando la información para conocer el funcionamiento de este espacio virtual.

La investigación también señaló que los niños que jugaron en Adventure Rock aprendieron muchas estrategias sociales y pudieron jugar con su identidad como no hubiera sido posible hacerlo en la vida real. Lo que más les gusta es la posibilidad de crear contenidos como video, cómics y música, así como las herramientas que les permite medir su prestigio y compararse con los demás.

A pesar de que no existen cifras exactas, el número de nińos y adolescentes que "vive" en estos mundos virtuales está creciendo vertiginosamente. Es el caso del mundo virtual Whyville (http://www.whyville.net), que se autodenomina como educativo con 2,3 millones de usuarios, que además de celebrar conciertos de música virtuales, introduce a los usuarios en una catástrofe ecológica para ayudar a promover la versión para niños del libro de Al Gore, An Inconvenient Truth.

Si bien Second Life (www.secondlife.com), con 12 millones de usuarios, está destinado a un público adulto y deja hacer en su mundo virtual, las páginas anteriormente nombradas han creado mundos virtuales con controles para proteger a los niños y adultos, atrayendo así a los papás. Aún así, en Second Life hay actividades para niños como la obra teatral y virtual del Mago de $\mathrm{Oz}$ que se montó en enero con decorados y avatares, con asistencia gratuita, aunque limitada a las cien personas que soporta un servidor de SL. En YouTube se podía ver el trailer de la obra así como una entrevista a algunos avatares de la obra.

Un mundo virtual muy conocido es Club Penguin (www.clubpenguin. com) que se patrocina por suscripciones y con venta de ropa, no tiene nada de publicidad, pero está en inglés. Club Penguin, que ha tenido un crecimiento espectacular, y pone especial énfasis en el juego interactivo y la socialización, fue comprado por Disney y va destinado a niños de entre 6 y 14 años.

Así, Club Penguin es un mundo virtual que funciona como un modelo freemium, es decir, se puede participar en el mundo virtual de manera gratuita pero sólo las suscripciones de pago podrán vestir a los pingüinos, decorar sus iglús o conocer, primero antes que nadie, los nuevos sitios que se van creando en este mundo virtual. 
Los nińos reciben un avatar en forma de pingüino, entrando en un mundo virtual infantil en el que pueden jugar, hacer amigos y charlar en sus iglúes o en las zonas comunes. Es un entorno virtual basado en la ciudad de Kelowna (Canadá) en el que los papás cuentan con la seguridad por las reglas de comportamiento que la propia compañía garantiza. En Club Penguin se aplican medidas disciplinarias que apartan temporal o definitivamente a los pingüinos que no respetan a otros pingüinos. Además, impide la revelación de información personal de cualquier tipo y las conversaciones inadecuadas en el chat.

En Club Penguin se requiere que los papás den su dirección de e-mail para activar la cuenta y la contraseña respectiva. Es curiosa la característica que ofrece su sala de chat ya que los niños sólo pueden utilizar palabras previamente habilitadas por el sistema. Los juegos les permiten acumular fichas y coleccionar pufless (unas mascotas pequeñas y redondas). Sus juegos tienen muchas posibilidades de interacción, y cuando el niño cumple tareas y acumula puntos le dan medallas y cartas de felicitación.

Club Penguin incentiva la creatividad y la cooperación, y además todos son pingüinos, por lo que no hay diferencias que discriminen. Ello resulta bastante atractivo tanto para los nińos como para las niñas, en contra de lo que habitualmente ocurre en los videojuegos.

Otro mundo virtual conocido es Disney's Toons Town (http://play.toontown. com/webHome.php). Mención especial merece el caso de un mundo virtual para nińos de Disney, Virtual Magic Kingdom (vмк) que es el primer mundo virtual para nińos que acaba de cerrar el 12 de mayo. vmK era un mundo virtual online, donde se creaba un avatar, el nińo exploraba un gigantesco parque de atracciones, chateaba y podía hacer amigos. Miles de personas clamaron en Internet para que Disney reconsiderara esta decisión. Este mundo virtual se abrió en mayo de 2005 como un espacio temporal de marketing, pero con el gran número de registros que obtuvo se decidió seguir captando nuevos usuarios y extender la campaña publicitaria. Como Disney contaba con diferentes mundos virtuales con más tecnología decidió cerrar vMK pero ha recibido miles de comentarios tanto de niños como de papás señalado que sus hijos están muy afectados porque hacían de ese espacio un espacio de vida social. Se armó una campaña contra su decisión (10,000 firmas).

Este mundo virtual creó un componente de unión emocional a sus miembros y que ahora "destruye" por querer rentabilizar nuevos desarrollos. Además esa comunidad no podrá contactarse de nuevo ya que la política de protección de menores les asegura el anonimato. 
Disney invirtió en enero de este año 100 millones de dólares en mundos virtuales infantiles, buscando crear por lo menos diez distintos. Disney se ha dado cuenta de que el ocio infantil en mundos virtuales es una mina de oro gracias a la enorme cantidad de público que pueden alcanzar y lo fácil que es fidelizar e influir en los niños.

Otro mundo virtual es Panfu (http://www.panfu.es), en el que los niños de entre 8 y 12 años juegan en línea, aprenden inglés jugando, encuentran la posibilidad de entrar en contacto en el chat con niños de su misma edad y de hacer amigos en un chat seguro, y cuidan de su mascota virtual (un oso panda). Cada niño puede estilizar su panda y decorar su casa en el árbol. En los juegos educativos se fomentan la habilidad y la capacidad de reacción. Una figura virtual les quita el miedo al Inglés y entrena con ellos la pronunciación y las palabras. Además, es un sitio libre de publicidad y gratuito. Pero si se tiene el paquete oro ( $\$ 160$ pesos al mes) se puede estilizar al panda, y decorar su casa entre otras cosas. Está su versión en alemán, que registra en cuatro meses un millón de usuarios que desea aprender castellano. Gracias a su mundo virtual los niños aprenden el español mientras decoran sus casas, visten los avatares y chatean.

Para los niños, en ocasiones, el mundo virtual puede ser más atractivo que el mundo real. Es cierto que participar en juegos imaginarios en un mundo virtual puede ser una experiencia de aprendizaje social positiva, pero no reemplaza al mundo real. Los nińos y los papás siempre deben recordar la importancia de interaccionar con niños y adultos, y aprender de otras personas cosas reales de la vida real.

\section{REDES SOCIALES}

Los sitios Web de redes sociales (social networking sites) son el lugar de encuentro que está de moda entre los niños de entre 9 y 12 ańos, los adolescentes y los veinteañeros. Estos sitios permiten que las personas intercambien información personal, usar blogs, chat o correo electrónico para su comunicación.

Las redes sociales son un fenómeno social y que afecta prácticamente a casi todos los países. El sitio japonés Mixi (http://mixi.jp) asegura que tiene ocho millones de usuarios, mientras que el chino Xiaonei (http://www.xiaonei.com), cuenta con seis millones, y el sitio coreano Cyworld (http://us.cyworld.com), con 18 millones de miembros, prácticamente el $85 \%$ de los internautas de Estados Unidos. 
Las redes sociales vivieron su explosión el año pasado, aunque también han tenido que afrontar cuestiones delicadas como la intrusión en la vida privada de sus usuarios. Durante el 2007, de entre diez palabras buscadas en Google, siete son de sitios de redes sociales. Esto indica que no ha parado de crecer. Por ejemplo, MySpace (http://mx.myspace.com) cuenta con más de ciento diez millones de usuarios y creció el año pasado un 30\%. Según la empresa ComScore (http://www.comscore.com), las webs de redes sociales recibieron cerca de quinientos millones de usuarios el año pasado.

El problema de la privacidad es un aspecto muy cuestionado cuando se habla de redes sociales (y más tratándose de niños). El problema estriba cuando el usuario ve cómo sus datos personales circulan por Internet sin control prácticamente. Por ejemplo, la red social Facebook (http://www.facebook.com), dio marcha atrás a su nueva herramienta de publicidad debido a las protestas de los usuarios que veían como la empresa proporcionaba demasiada información sobre las compras que hacían a sus contactos.

El furor por las redes sociales ha tenido su reflejo en las ingentes inversiones financieras. Por ejemplo, Microsoft compró al año pasado Facebook por 240 millones de dólares, lo que coloca el valor de mercado de la red social a una escala similar al de General Motors.

Existen muchos aspectos positivos del uso que hacen los niños de las redes sociales. Por ejemplo, las buenas conexiones que han establecido por Internet a través de redes sociales y salas de chat se traducen en buenas conexiones en el mundo real. La gran parte de la comunicación que se produce en estos espacios virtuales es entre nińos que ya se conocen personalmente y es una manera de reunirse en vez de acudir a la tienda de la esquina o a un centro comercial, con el peligro que también conlleva.

Además, hay estudios, como los de Lenhart y Madden (Adolescentes, privacidad y redes sociales en Internet: cómo controlan sus identidades e información personal en Internet los adolescentes en la era de MySpace, Pew Internet and American Life Project, en su conferencia del 18 de abril de 2007) que señalan que los usuarios frecuentes de las redes sociales, suelen ser lo más dinámicos en las actividades of line, las tradicionales. Para estos niños, las redes sociales en Internet pueden ayudarles a desarrollar confianza y apoyo social, según un grupo de investigaciones, encabezados por Ellison en el año 2006.

Las redes sociales son un medio muy útil para que los nińos expresen sus emociones o incluso averigüen más datos sobre los niños o jóvenes que acaban de conocer de manera presencial. Por ejemplo, después de conocer en persona 
a un nińo, se puede visitar el sitio web de ese niño para ver sus gustos y decidir si se trata de una persona con la que el niño pudiera estar interesado en entablar una amistad.

La comunicación entre niños de diferentes culturas del mundo es ahora en tiempo real y se puede saber sobre sus vidas con video, audio, mapas vía satélite y mensajes de texto. Es decir, es más fácil el contacto con una mayor diversidad cultural. Tampoco debemos de perder de vista su futuro, ya que vivimos en un mundo conectado y la fluidez que existe entre las comunicaciones en Internet y las tradicionales les acostumbra a mantener un tipo de relaciones que les va a ser de gran provecho cuando tengan que trabajar de manera remota, en teletrabajo, por ejemplo.

Más allá de las redes sociales convencionales en Internet, ha llegado la última versión de redes sociales móviles, que informan a los usuarios en su celular (por mensaje de texto, correo electrónico o mensaje telefónico) cada vez que un usuario en cualquiera de las redes sociales en Internet envíe una nueva información. Una de estas redes sociales es Queep.net (http://www.qeep. net). Se trata de una aplicación para celular que permite a sus usuarios chatear, enviar y compartir fotos, jugar online y crecer la red de contactos a través de una red social.

Otras redes sociales permiten a los usuarios reportar su ubicación y envían un mensaje de texto (y foto) a los teléfonos de todos los miembros de su red social, revelándoles su ubicación exacta (no está nada mal para los papás ya que conocen en tiempo real dónde están sus hijos). También permite que los usuarios anuncien su ubicación a un "amigo de su amigo" o reuniones en un radio de 10 cuadras con un mensaje de texto automático.

Todo esto es posible gracias a que la nueva generación de celulares ofrece conexiones rápidas con Internet, celulares 3G (tercera generación) que permiten a los usuarios hacer con ellos casi todo lo que hacen en las computadoras, como mensajes, compras electrónicas, contactos sociales, búsquedas en Internet y juegos de video.

Además de la práctica habitual entre niños de crear blogs, también pueden crear páginas web personales en sitios web de redes sociales que alojan servicios como MSN Spaces (http://home.services.spaces.live.com/), y Friendster (http:// www.friendster.com), Hi5 (http://www.hi5.com), entre otros.

Estos servicios son muy populares entre los niños y jóvenes, e incluyen información como fotografías, videos, información personal (nombre, apellidos, lugares y teléfonos celulares). Se puede diseñar al antojo del usuario y 
compartirlo con quien se desee. En una red social hay desde un blog donde el niño refleja lo que piensa hasta listas musicales.

Otra red social muy conocida es Totspot (http://totspot.com), que una vez registrados por sus papás, los nińos los chicos disfrutarán con su espacio virtual para publicar sus videos, imágenes, su diario. En Totspot los perfiles solo podrán ser vistos por la comunidad, y los niños podrán ser contactados únicamente por otros miembros. La autorización para ello podrá ser dada por el mayor que ha registrado al usuario en la red social, o se puede predeterminar el perfil para que pueda ser únicamente visto por los contactos ya autorizados de los niños.

Otra red social que tiene que ver con mascotas es Mojikan (http://www. mojikan.com) en la que los niños pueden crear su mascota y mantener con ella una relación interactiva en un mundo virtual. Es una red social en la que el protagonismo es la mascota del nińo, que conoce a otras mascotas y va creando su propia red de amigos, gracias al perfil y personalidad que definan ellos.

Para los que están preocupados con lo que hacen los niños en las redes sociales hay una página Imbee (http://www.imbee.com) con dos servicios diferenciados: uno para los papás y otro para los hijos. Los padres pueden crear perfiles para sus hijos, pudiendo validar y observar todo lo que hace dentro (amigos, mensajes, actividades, fotos). Los niños, por su parte, además de estar controlados, pueden compartir fotos, escribir un blog y comunicarse con otros amigos de Imbee. Ahora bien, la opción de escribir blogs no es gratuita.

\section{Correo eleCtrónico, MENSAJERÍA INSTANTÁNEA, FOROS, BLOGS Y CHAT}

Es común que los servicios que hospedan redes sociales proporcionen diferentes medios para la comunicación interpersonal, como la creación de blogs y servicios de mensajería instantánea. Hoy en día somos conscientes de que el correo electrónico, los foros, los blogs y el chat se han vuelto una forma de comunicación muy habitual entre los niños. Normalmente, el uso que le dan los niños es para comunicarse con otros niños que se localizan al otro lado del planeta, o también con los compañeros con los que se cruzan a diario por el pasillo de la escuela.

El uso del correo electrónico aporta enormes posibilidades al aprendizaje, a la motivación y al desarrollo de habilidades comunicativas en los primeros ańos de vida. La posibilidad de utilizar esta nueva herramienta es novedosa y relevante, cobrando relevancia en los primeros años de primaria, desde el momento en que se presenta como una forma más de comunicación y expresión. 
El correo electrónico se consolida como un eje de las competencias de lectura y escritura que empieza a desarrollar, y que se ha convertido en una herramienta de comunicación constante entre los niños.

Para introducir al niño en el uso del correo electrónico se les puede ayudar a los niños a escribir sobre sus eventos cotidianos. No quiere decir que el correo electrónico reemplace las tarjetas o las cartas personales pero puede suplementarlos, permitiendo respuestas más inmediatas. Al principio se les puede dictar un mensaje, y con el tiempo podrá adquirir habilidad en el uso del teclado.

Existe una web, Zilladog (http://www.zilladog.com) que puede ser el lugar ideal para crear las cuentas de correo electrónico para los niños. Además de tener una apariencia muy agradable, con un diseño colorido y fácil de entender y manejar ofrece varias herramientas que ayudan a los papás a controlar las actividades de sus hijos, como por ejemplo, recibir todos los correos enviados o controlar la lista de contactos, evitando así que reciba spam de otras cuentas. También dispone de videos y contenidos creados para ellos, para que no tengan que salir de la página.

Existen diferentes empresas que ofrecen el servicio de mensajería instantánea. Si bien empezaron como un servicio para jóvenes y adultos, también los niños son usuarios de estos servicios: ICQ (http://www.icq.com), MSN Messenger (http://messenger.latino.msn.com), Yahoo Messenger (http://www.yahoo.com), Skype (http://www.skype.com), entre otros.

La mensajería instantánea permite la comunicación sobre todo a través de mensajes de texto en tiempo real con otras personas del mundo. Normalmente, funcionan con listas de contacto, donde cada persona usa un sobrenombre o nick. La lista de contactos se llena con personas conocidas o en base a buscadores de personas, pudiendo agregar a cualquier usuario del mundo, aunque se le debe solicitar permiso a través de un mensaje automático y aceptarlo, por supuesto.

Los contactos que tenga el niño podrán enviarle mensajes, enviar archivos y efectuar comunicación por voz y videoconferencia (si se dispone de micrófono, altavoces y cámara en la computadora). Muchos niños se comunican con sus amigos y compańeros de colegio de esta manera, pero también pueden contactar a desconocidos. Por ello, es importante ser cuidadoso con las personas con las que el niño tiene en su lista de contactos. Hay que ser precavidos y revisar esta lista y cuidar los archivos que se intercambian que son posibles foros de virus.

Las salas de chat son espacios virtuales donde establecen comunicación varios usuarios a la vez y están moderados por un usuario o por un sistema 
de moderación automático, o también puede darse el caso de que sea una sala sin moderador. Su funcionamiento consiste en preguntar al nuevo usuario cuándo acceder su nombre y se abre una ventana en donde todos los usuarios conectados a la sala del chat pueden escribir mensajes, que son transmitidos a los demás usuarios.

Hay que ser conscientes de que los niños pueden entrar en las salas no moderadas, es decir, no existe alguien que controle el contenido de la discusión. Por eso, es recomendable que esté presente cuando el nińo ingrese en este tipo de servicios o permitirle el acceso sólo en aquellas salas que el adulto conoce y que son muy valiosas ya que estimula en el niño su capacidad de reflexión y argumentación. En las mismas escuelas, hay materias en las que los maestros habilitan este tipo de salas de chat para que se continúe con la discusión abierta en clase, y las intervenciones del niño se evalúan como otra actividad más.

Es importante y fundamental reiterar la vigilancia de los papás sobre sus hijos cuando entren en salas de chat ya que a pesar de que muchas están alojadas en páginas para niños, es probable que accedan adultos, y algunos no con buenas intenciones. Más adelante, en los portales educativos y de entretenimiento, así como en las páginas específicas de juegos encontrará salas de chat, además de los juegos, materiales y recursos multimedia educativos.

Los foros de mensajes por lo general agrupan a personas con intereses comunes. Estos foros son páginas web en donde se puede escribir mensajes que se ven en la página del foro, y obtener respuestas y comentarios de un tópico en especial.

Puede encontrar comunidades interesadas en salud, educación, música, y mucho más. Los foros normalmente atraen a personas de diferentes edades y entornos, por lo que los niños también son un público atento a este servicio. Los foros de los niños están relacionados con los juegos, las series de televisión, sus cantantes favoritos. Al igual que en las salas de chat, también hay que cuidar a qué foros entran los niños y las personas que acceden a él.

Los diarios on line o blogs son uno de los servicios más exitosos que ofrece Internet. A través de páginas web, los niños pueden compartir con otros lo que les sucede en su vida diaria. Hablar de blogs es hacerlo también de escribir y leer en la red, lo que le da una doble dimensión de creación, identidad y autoría, que los hace más que una página web. Con el blog se publica información con una facilidad e inmediatez incomparable, y se accede a información o comentarios de los demás. Los blogs son el fenómeno más literario y creativo de la red.

Cualquiera puede registrar un blog y empezar a publicar en él, lo que lo 
llevará a compartir imágenes o vídeos, expresar ideas y así como recibir comentarios y mantener discusiones públicas.

Hay que tener cuidado con este servicio, ya que cualquier persona que navega por Internet puede leer la información que se entrega a través de estos blogs, por lo tanto, es recomendable aconsejar a los niños tener cuidado con los contenidos que publican.

Existen plataformas específicas para crear blogs, y en algunas páginas de entretenimiento para niños ofrecen la posibilidad de crear uno. También en algunas redes sociales es posible crear blogs.

Un blog que está orientado a los niños es One Happy Reality (http://onehappyreality.blogspot.com). Este es un espacio para padres de familia en el que podrán consultar artículos sobre los cuidados que sus niños necesitan, películas recomendadas y música para estimularlos. Aquí encontrarán encuestas sobre datos de los niños, videos y fotos. Resulta toda una variedad para pasar un rato entretenido y enriquecedor.

Es muy habitual entre los niños emplear herramientas especialmente diseñadas donde se puede publicar en Internet fotografías exclusivamente. Es el caso de Foto Pages (http://www.fotopages.com), un blog de fotografías, el photo blogging, y la famosa página de Flickr (http://www.filckr.com), donde se puede almacenar álbumes enteros de fotografías y ponerlas a disposición de todo el mundo si se desea. Afortunadamente, está la opción de que sean vistas exclusivamente por la lista de contacto que se tenga (privado). Para poder subir las fotografías, en ambos casos, es necesario registrarse.

\section{CONCLUSiones}

Los cambios tecnológicos de las últimas décadas han sido objeto de estudio por investigadores de diferentes áreas que han analizado el impacto de las tecnologías en las formas de comunicación y relación de todas las personas y edades. Concretamente, Internet ha supuesto un gran potencial para el entretenimiento, el desarrollo y formación de los niños, así como su nueva manera de comunicarse y de relacionarse con sus amigos y hasta desconocidos.

Las redes sociales, los blogs, los mundos virtuales son capaces de desarrollar nuevas habilidades y equilibrar su campo de acción social desde el momento en que logran que los niños se conozcan mejor y profundicen amistades fuera de Internet, incluso con personas que jamás conocerán en persona (sobre todo por estar geográficamente distantes y difícilmente). 
Lo que debemos tener claro es que las relaciones sociales creadas en Internet no sustituyen a las relaciones personales. De hecho, las comunidades creadas en la Red se fortalecen y desarrollan una fuerte identidad cuando se da la ocasión de encontrarse cara a cara. En sitios como Meetup.com se fomentan los encuentros personales. Eso sí, en el caso de los niños hay que tener especial cuidado con las amenazas que circulan por Internet. Por ello, la obligación de los papás será estar al pendiente de los movimientos de sus niños en la Red e involucrarse con ellos en sus actividades.

Los papás no pueden prohibir a sus hijos que estén en redes sociales cuando todos sus amigos se comunican a través de ellas. Para ellos, no estar en una red social supone una presión social por estar "out". Lo que pueden hacer los papás es advertirles y aconsejarles para no caer en determinadas prácticas y en no dar información personal ni familiar a desconocidos. Además, los adultos deben entender qué es lo que ocurre en una red social y mundo virtual y ver quiénes son sus amigos.

La preocupación por este tema es tal que se recomiendan a estas redes sociales y mundos virtuales que desarrollen sus políticas propias recogiendo tanto lo que los usuarios pueden esperar de sus servicios como el comportamiento que se espera de ellos. También se recomienda que estos sitios se asocien con fundaciones que se dediquen a vigilar que se está haciendo buen uso de Internet.

Lo cierto es que la influencia de Internet en los niños y adolescentes no ha hecho más que empezar. No es una moda pasajera ya que nacieron en la era digital. Son los nativos digitales.

\section{REFERENCIAS}

AMIPCI (2008). Estudio de nuevas tecnologías de Internet en México 2008. Disponible http://www.AMIPCI.org.mx/temp/EstudioAMIPCInuevastecnologiasdeInterneteMexico2008RESUMENEJECUTIVO-0170012001210946955OB.pdf. Fecha de consulta 23 de mayo de 2008.

AMIPCI (2008). "Hábitos de los usuarios de Internet en México 2007”. Disponible en http://amipci.org.mx/temp/pdf-0315967001193426740OB.pdf. Fecha de consulta: 10 de julio de 2008.

Ellison, N., Steinfie, C. \& Lampe, C. (2006). Spatially Bounded Online Social Networks and Social Capital: The Role of Facebook ("Redes sociales espacialmente unidas y el capital social: el papel de la red social Facebook"). Trabajo presentado en la Conferencia Anual de la Asociación Internacional de Comunicación (ICA, por sus siglas en inglés), 19 al 23 de junio de 2006, Dresden, Alemania. 
Fundación Telefónica y Universidad de Navarra. Generaciones Interactivas en Iberoamérica. Niños y adolescentes frente a las pantallas. Retos educativos y sociales. Disponible en http://www.educared.org.ar/tecnologia/generacion-i/index.php?q=node/220. Fecha de consulta: 24 de mayo de 2008.

Gabelas Barroso, J.A. \& Lazo, C. (2008). Consumos y mediaciones de familias y pantallas. Nuevos modelos y propuestas de convivencia. Programa Pantallas sanas del Gobierno de Aragón. España. Libro electrónico disponible en http://www. quadernsdigitals.net/index.php?accionMenu=hemeroteca.VisualizaArticuloIU. visualiza\&articulo_id=10459. Fecha de consulta: 24 de mayo de 2008.

IAB México (2007) "Asuntos de familia. La evolución de los medios de comunicación de la Familia Global en la Era Digital". Disponible en http://www.iabmexico. com/downLoads/FamilyAffair.pdf. Fecha de consulta: 8 de mayo de 2008.

IAB México (2008). "Estudio de consumo de medios digitales en México". Disponible http://www.iabmexico.com/downLoads/IABmxConsumoMediosDigitales_2008.pdf. Fecha de consulta: 20 de julio de 2008.

IAB México (2008). "Rivaliza Internet a la televisión en preferencia de consumo de medios: IAB México". Disponible en http://www.iabmexico.com/downLoads/ PR_ConsumoDeMediosDigitales_2008.pdf. Fecha de consulta: 17 de julio de 2008.

Forrester research (2008). "Getting Real Work Done In Virtual Worlds". Disponible en http://www.forrester.com/Research/Document/Excerpt/0,7211,43450,00. html Fecha de consulta: 10 de abril de 2008.

Lenhart, A., \& Madden, M. (2007). Teens, Privacy \& Online Social Networks: How teens manage their online identities and personal information in the age of $M y S p a c e$ ("Adolescentes, privacidad y redes sociales en Internet: cómo controlan sus identidades e información personal en Internet los adolescentes en la era de MySpace”). Pew Internet and American Life Project. 18 de abril de 2007.

Mediascope Europe (2008). "Familias digitales 2008". Disponible en: http://www. marketingdirecto.com/estudios/EIAA\%20Familias\%20Digitales\%202008\% 20-\%20Еspa\%C3\%B1a\%2010.04.08.pdf. Fecha de consulta 18 de mayo de 2008.

Padrón Arredondo, L. (2008). "Nuevas Tecnologías de la Información y su repercusión en los diferentes niveles de la educación", en Revista Digital Universitaria, Volumen 9, Número 2. Disponible en http://www.revista.unam.mx/vol.9/num2/ art09/int09.htm. Fecha de consulta: 11 de junio de 2008.

Rojas, G. (2004). “Generación net. ¿estamos preparados?”, en PC World. Disponible en: http://www.pcworld.com.ve/n25/articulos/generacion.html Fecha de consulta: 10 de abril de 2008.

Sartori, G. (1998). Homo Videns. La sociedad teledirigida. Espańa: Taurus.

Tapscott, D. (1998). Creciendo en un entrono digital. Colombia: McGraw-Hill. 